\title{
Impact of Social Networks on Diffusion of Products
}

\author{
Yudai Arai \\ Graduate School of Science and Engineering, \\ Aoyama Gakuin University, Japan \\ Tomoko Kajiyama \\ Department of Industrial and Systems Engineering, Collage of Science and \\ Engineering, Aoyama Gakuin University, Japan \\ Noritomo Ouchi \\ Department of Industrial and Systems Engineering, Collage of Science and \\ Engineering, Aoyama Gakuin University, Japan
}

\begin{abstract}
In light of the rapid growth of social networks around the world, this study analyses the impact of social networks on the diffusion of products and demonstrates the effective way to diffuse products in the society where social networks play an important role. We construct a consumer behaviour model by multi-agent simulation taking the movie market as an example. After validating it by using data from 13 US movies, we conduct simulations. Our simulation results show that the impact of social networks on the diffusion differs according to the customers' expectations and evaluation for a movie. We also demonstrate the effective weekly advertising budget allocations corresponding to the types of movies. We find that the difference of weekly advertising budget allocations gives greater impact on the diffusion with the growth of social networks. This paper provides firm's managers with important suggestions for diffusion strategy considering the impact of social networks.
\end{abstract}

Keywords: Social networks, diffusion strategy, consumer behaviour model, multiagent simulation.

\section{INTRODUCTION}

ocial networking services such as Twitter and Facebook have grown rapidly around the world and are generating a significant impact on changing consumer behaviour and the diffusion process of products. Contemporarily, many firms utilise social networking services to market their products. By optimally using social networking services, firms may diffuse their products more widely, even on a limited budget. Such a strategy will be critical, especially for firms in emerging economies, whose budgets are relatively small compared to those of large firms in developed economies. In order to devise an effective diffusion strategy, understanding the impact of social networks on consumer behaviour and the diffusion process of products is essential.

There are a large number of studies that attempt to clarify consumer behaviour and the diffusion process of products (Mansfield, 1961; Bass, 1969;

Journal of Technology

Management for Growing Economies

Vol. 5 No. 1 April 2014 pp. $35-50$

\section{ChITKARA 司 UNIVERSITY}

C) 2014 by Chitkara University. All Rights Reserved. 
Arai, Y.

Kajiyama, T.

Ouchi, N.

Mahajan et al., 1990; Meyer, 1994; Libai et al., 2009). For example, Bass (1969) developed a single first-purchase diffusion model, which assumes two types of adopters: innovators and imitators. Many researchers have developed diffusion models based on this model. However, they have not considered the role of social networks on consumer behaviour. Thus, how social networks influence consumer behaviour and, subsequently, the diffusion of products remains unclear.

Some researchers have attempted to link consumer behaviour and firms' strategies (Kamimura et al., 2006; Tilman et al., 2007; Duan et al., 2008). For example, Duan et al. (2008) used a dynamic simultaneous system to demonstrate how word-of-mouth (WOM) on the Internet influences consumer behaviour in the movie market. They revealed that there is a positive relationship between WOM volume and sales figures, and suggested that stimulating the volume of WOM about a product or service is an effective diffusion strategy. In addition, other studies have shown that the effective advertisement of products is important for increasing consumers' willingness to pay for those products (Tsui, 2012).

Additionally, Kamimura et al (2006) constructed a consumer behaviour model concerning the movie market and analysed the effective use of an advertising budget. During the advertising period (which starts a few weeks before a movie is released and lasts until the final week a movie is in theatres), firms allocate a certain amount of their budget to advertising each week. Kamimura et al (2006) demonstrated the impact of the different patterns of weekly advertising budget allocation on the cumulative number of movie viewers. However, there are some limitations in the study. It does not consider the existence of social networks. Furthermore, the characteristics of the movies are not considered, although such product features may well be a critical element of an effective diffusion strategy. Some research (Mittal et al., 1999; Plouffe et al., 2001) has argued that consumer attitudes and behaviours are affected by product characteristics. Given this, it is important to consider differences in product characteristics to devise effective diffusion strategies.

Given the above, the objectives of our study are as follows: (i) to clarify how social networks impact the diffusion process of products corresponding to product characteristics by constructing a consumer behaviour model that considers the impact of social networks, and (ii) to demonstrate effective diffusion strategies in order to increase the number of adopters of products. This study considers the movie market as a target market because it is strongly influenced by the effects of WOM and, is therefore, suitable for our study.

In section 2, we propose a consumer behaviour model that incorporates social networking effects. In section 3, we validate the accuracy of our 
proposed model using empirical data of 13 US movies, clarify how social networks influence the diffusion process of products, and demonstrate effective diffusion strategies. Finally, in section 4 , we briefly summarises the new findings, discuss strategy implications for firms, and provide some suggestions for future research.

\section{MODEL CONSTRUCTION}

In this study, we developed a consumer behaviour model considering social networks' effects by multi-agent simulation using the movie market as an example ${ }^{1}$. Multi-agent simulation is a class of computational models for simulating the actions and interactions of agents to assess their effects on the system as a whole. Multi-agent simulation is an especially appropriate model for observing individual actions and interactions between consumers in society. Because this study is geared towards constructing a model that considers the effects of individual agents on a society, multi-agent simulation is suitable. We used the software 'artisoc' produced by Kozo Keikaku Engineering Inc. to conduct the simulations. In our model, 1,000 agents are created in a grid size of $50 \times 50$ cells.

According to Kamimura (2006), internal and external factors may contribute to consumers' motivations for watching a movie. Internal factors represent consumers' interests in movie, and external factors consist of advertising and WOM. Further, the degree to which value is placed on internal or external factors varies by consumer. For example, while some consumers watch a movie once they have developed an interest in it, others may refer to WOM before making a decision regarding the film. To account for these variations, we set the decision-making process as follows: agent i decides whether or not to watch a movie at week t, by comparing the weighted sum of 'individual preference' $\left(P_{i, t}\right)$ and 'effects from advertising and WOM' $\left(E_{i, t}\right)$ with 'individual threshold' $\left(T_{i}\right)$. By using weighted parameter $\left(a_{i}\right)$, the condition where agent $i$ decides to watch a movie is defined as depicted in inequality (1).

$$
a_{i} \cdot P_{i, t}+\left(1-a_{i}\right) \cdot E_{i, t}>T_{i}
$$

To account for characteristics of individual consumers, we assume is a random number between 0 and 1 . If is close to 1 , agents value their interests for a movie. On the other hand, agents value WOM if is close to 0 . 'Individual preference' () represents agent $i$ 's degree of preference for the movie. $P_{i, t}$ is computed with equation (2).

$$
P_{i, t}=(p b+a d v+p r e) \cdot F^{P}(t) \cdot I_{i}^{P} \cdot D_{i}^{P}
$$

Impact of Social

Networks on Diffusion 
Arai, Y.

Kajiyama, T.

Ouchi, N. where, $p b$ is the effect of production budgets, $a d v$ represents the effect of advertising, pre depicts the effect of previous movies and original novels, $F^{p}(t)$ is the time variation of consumers' interests in a new movie, $I_{i}^{P}$ represents the individuality of agent $i$, and $D_{i}$ is a dummy variable that denotes whether or not agent $i$ has an interest in the movie's genre $\left(D_{i}=1\right.$ if agent $i$ has an interest, $D_{i}=0$ if otherwise).

The variables $p b, a d v$ and pre are rated on a scale of one to ten. We consider $p b, a d v$ and pre to be components of $P_{i, t}$ because they represent key factors related to a movie's attractiveness. Because consumers' interests in a movie wane as time passes, $F^{p}(t)$ is a decreasing function of t. In our model, we set $F^{p}$ $(t)=0.94^{t}$ following Kamimura et al (2006). With respect to the value of $I_{i}^{P}$, we assign agents a random number between 0 and 1 because receptivity can vary among consumers.

Consumers' film genre preferences also influence their decision to watch a movie. Therefore, we created a dummy variable $\left(D_{i}\right)$ to represent whether or not agent $i$ is interested in the genre of the movie. To determine the percentage of agents who are interested in the movie genre, we referred to the results of a questionnaire provided by Kamimura et al (2006), as denoted in Figure 1. Figure 1 , for example, shows that the percentage of consumers who are interested in the Action/Adventure movie is 69\%. Following Kamimura et al (2006), we use the percentages outlined in Figure 1 as relevant data.

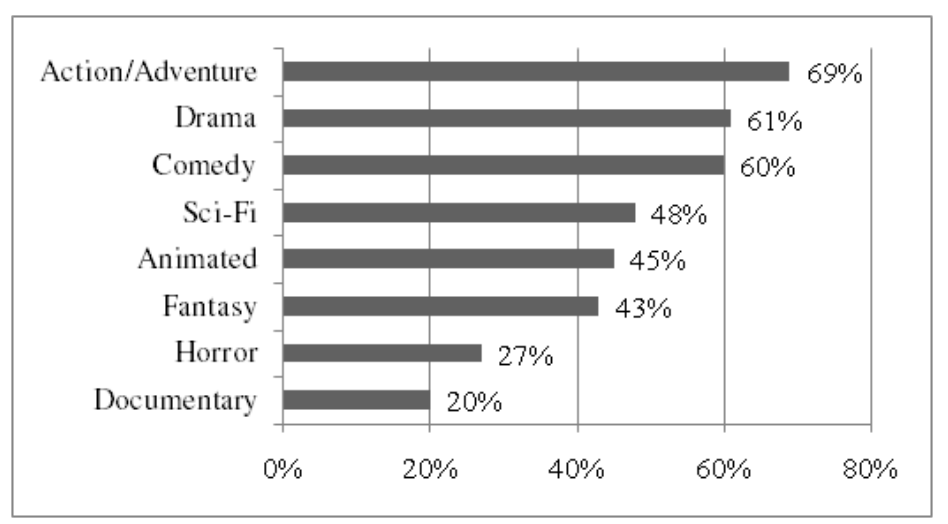

Figure 1: Percentage of consumers who are interested in the genre of the movie Source: Kamimura et al (2006)

'Effects of advertising and WOM' $\left(E_{i, t}\right)$ is the sum of the 'effects of advertising' $\left(A_{i, t}\right)$ and the 'effects of WOM' $\left(W_{i, t}\right)$ as depicted in equation (3).

$$
E_{i, t}=A_{i, t}+W_{i, t}
$$


is computed by equation (4).

$$
A_{i, t}=a d v \cdot R^{A} \cdot I_{i}^{A} \cdot G^{A}(t)
$$

where $R^{A}$ is the reliability of mass media, $I_{i}^{A}$ represents agent $i$ 's responsiveness to advertising, and $G^{A}(t)$ relates to time variation concerning the effect of advertising.

Sources of information, such as mass media and WOM, differ in terms of their respective reliabilities. In this model, we assume $R^{A}=1 . I_{i}^{A}$ is a random number between 0 and 1 because receptivity can also vary among consumers. Because the effects of advertising decrease as time passes, we set $G^{A}(t)=B^{A} \cdot F^{A}(t) . \quad B^{A}$ is a base value for time variation related to the advertising effect. According to Miyata and Ikeda (2008), who investigated how consumers gather information related to movies, $30.6 \%$ of all consumers seek information related to movies from advertising. Therefore, we set $B^{A}$ $=0.306$ in this model. $F^{A}(t)=0.7(\mathrm{t}<0)$ and $F^{A}(t)(t \geq 0)$, in accordance with Kamimura et al (2006). In section 3.3, we change $F^{A}(t)$ to correspond with advertising budget allocation patterns.

With respect to $W_{i, t}$, we consider three sources of WOM: 'neighbours', 'Internet sites', and 'social networks'. $W_{i, t}$ is the sum of the effects of neighbours' WOM $\left(\sum_{j=1}^{N_{N}} w_{i, j, t}\right)$, the effects of the Internet's WOM $\left(\sum_{k=1}^{N_{I}} w_{i, k, t}\right)$ and the effects of social networks' WOM $\left(\sum_{l=1}^{N_{S}} w_{i, l, t}\right)$ as depicted in equation (5).

$$
W_{i, t}=\sum_{j=1}^{N_{N}} w_{i, j, t}+\sum_{k=1}^{N_{I}} w_{i, k, t}+\sum_{l=1}^{N_{S}} w_{i, l, t}
$$

where $w_{i, j, t}, w_{i, k, t}$ and $w_{i, l, t}$ represent the respective WOM effects agent $i$ received from agent $j, k$ and $l$, respectively $N_{N}, N_{I}$ and $N_{S}$ respectively represent the number of agents who can influence the impact of neighbours' WOM, the Internet's WOM, and social networks' WOM on agent $i$.

Although consumers can acquire information widely via the Internet, there are physical limitations associated with receiving WOM from neighbours. As a result, the number of agents who can affect the impact of Internet's WOM is greater than the number of agents that can influence neighbour's WOM. As such, we model $N_{N}$ and $N_{I}$ within $3 \times 3$ cells and $21 \times 21$ cells around agent $i$, respectively. Social networks represent specific connections between consumers on the Internet. Therefore, we assume that $N_{S}$ is the number of agents who have a link with agent $i$ and are within $21 \times 21$ cells around agent $i$.

A scale-free network (Barabasi and Albert, 1999) can be used to describe social networks. A scale-free network is a network with the property that the number of links originating from a given node exhibits a power law distribution. The network denotes the condition that few consumers have a large number of

Journal of Technology Management for Growing Economies, Volume 5, Number 1, April 2014
Impact of Social

Networks on Diffusion

\author{
$(-39$
}


Arai, Y.

Kajiyama, T.

Ouchi, N. links, while other majorities have a few links. We use a scale-free network to create the links between agents, which denote social networks.

$w_{i, j, t}$ is computed as depicted in equation (6). $w_{i, k, t}$ and $w_{i, l, t}$ are computed in a similar manner.

$$
w_{i, j, t}=\left\{\begin{array}{c}
(p b+a d v+\text { pre }) \cdot R^{W} \cdot I_{i}^{w} \cdot O_{j} \cdot G^{W}(t) \text { (before release) } \\
\text { RatingScore } \cdot R^{W} \cdot I_{i}^{w} \cdot O_{j} \cdot G^{W}(t) \text { (after release) }
\end{array}\right.
$$

where $R^{W}$ represents the reliability of WOM, $I_{i}^{W}$ is agent $i$ 's responsiveness to ation in time related to the frequency with which an agent chats about the movie.

Following a movie's release date, the effect of WOM is largely contingent on the movie's rating score. However, consumers cannot obtain information concerning the movie's rating score prior to its release. Therefore, a movie's attractiveness prior to its release date is dependent on $p g, a d v$ and pre.

A rating score is an evaluation of a movie's value on a scale of one to ten, which is quoted from 'The Numbers' (The Numbers, 2011). Because the reliability of WOM $\left(R^{W}\right)$ can differ as a function of the strength of the connection between consumers, we assume that $R^{W}{ }_{\text {neighbors }}=2.0, R^{W}{ }_{\text {internet sites }}=$ 1.0 and $R_{\text {social networks }}^{W}=1.5$, respectively. $I_{i}^{W}$ is a random number between 0 and 1 because receptivity differs among consumers. Because agents' ability to spread information can also differ among consumers, $O_{J}$ is a random number around 1 , between 0.5 and 1.5. We assume that the effects of WOM decrease as time passes, and set $G^{W}(t)=B^{W} \cdot F^{W}(t) \cdot B^{W}$ is a base value of the WOM effect, which we set as $B^{W}{ }_{n e i g h b o r s}=0.32, \mathrm{~B}^{W}{ }_{\text {internet sites }}=0.16$ and $B^{W}{ }_{\text {social }}$ networks $=0.24$, respectively. Similar to $B^{A}$, we set the values of $B^{W}{ }_{\text {neighbors }}$ and $B^{W}{ }_{\text {internet sites }}$ in accordance with the work of Miyata and Ikeda (2008). We set $B^{W}{ }_{\text {social networks }}$ to be between $B^{W}{ }_{\text {neighbors }}$ and $\mathrm{B}^{W}{ }_{\text {internet sites }}$ because Miyata and Ikeda (2008) did not investigate the social networks. We considered the base value of social networks' WOM effect to be larger than that of the Internet but smaller than that of neighbours. Also in parallel with Kamimura et al. (2006), $F^{W}(t)=e^{t}(t<0)$ and $F^{W}(t)=0.94^{t}(t \geq 0)$. The parameters for $B^{W}$ and $R^{W}$ are outlined in Table 1.

Table 1: Differences among the three WOM sources

\begin{tabular}{|c|c|c|}
\hline WOM source & $R^{w}$ & $B^{w}$ \\
\hline Neighbour & $\begin{array}{c}\text { High } \\
\left(R_{\text {neighbors }}^{w}=2.0\right)\end{array}$ & $\begin{array}{c}\text { High } \\
\left(B^{w}{ }_{\text {neighbors }}=0.32\right)\end{array}$ \\
\hline Internet sites & $\begin{array}{c}\text { Low } \\
\left(R_{\text {internet sites }}^{w}=1.0\right)\end{array}$ & $\begin{array}{c}\text { Low } \\
\left(B^{w}{ }_{\text {internet sites }}=0.16\right)\end{array}$ \\
\hline Social networks & $\begin{array}{c}\text { Medium } \\
\left(R_{\text {social networks }}^{w}=1.5\right)\end{array}$ & $\begin{array}{c}\text { Medium } \\
\left(B_{\text {social networks }}^{w}=0.24\right)\end{array}$ \\
\hline
\end{tabular}

(): Parameters used in the model

Journal of Technology Management for Growing Economies, Volume 5, Number 1, April 2014 
The individual threshold is computed by equation (7).

$$
T_{i}=\alpha+\beta \cdot r
$$

where $\alpha, \beta$ refers to the respective coefficients that determine the individual threshold and $r$ is a random number between 0 and 1 .

Agents are characterised as innovators, early adopters, early majority, late majority, and laggards, in accordance with Rogers' diffusion theory (Rogers, 1962). The values of $\alpha$ and $\beta$ differ depending on these characteristics, as illustrated in Table 2.

Table 2: Parameters for individual thresholds

\begin{tabular}{|l|c|c|c|}
\hline Category & Proportion (\%) & $\boldsymbol{\alpha}$ & $\boldsymbol{\beta}$ \\
\hline Innovators & $2.5 \%$ & 4 & 1 \\
\hline Early adopters & $13.5 \%$ & 6 & 3 \\
\hline Early majority & $34 \%$ & 9 & 6 \\
\hline Late majority & $34 \%$ & 11 & 6 \\
\hline Laggards & $16 \%$ & 13 & 3 \\
\hline
\end{tabular}

\section{SIMULATION AND APPLICATION TO DIFFUSION STRATEGIES}

\section{Model Verification}

We validated the proposed model by comparing our simulation results with actual data related to the cumulative number of weekly movie viewers. To this end, we selected 13 movies (see Table 3). They include the top five movies in terms of box office take in 2010 and 'The King's Speech', the Academy Award winner for Best Motion Picture in 2010. The data in Table 3 are available at 'The Numbers (The Numbers, 2001).

Table 3: List of the 13 movies used in the study

\begin{tabular}{|l|c|}
\hline Title & Sales Figure \\
\hline Toy Story 3 & $\$ 415,004,880$ \\
\hline Alice in Wonderland & $\$ 334,191,110$ \\
\hline Iron Man 2 & $\$ 312,433,331$ \\
\hline The Twilight Saga: Eclipse & $\$ 300,531,751$ \\
\hline Inception & $\$ 292,568,851$ \\
\hline Harry Potter and the Deathly Hollows: Part I & $\$ 294,980,434$ \\
\hline Shrek Forever After & $\$ 238,319,043$ \\
\hline The Book of Eli & $\$ 94,822,707$ \\
\hline
\end{tabular}


Arai, Y.

Kajiyama, T.

Ouchi, N.

\begin{tabular}{|l|c|}
\hline Title & Sales Figure \\
\hline The Social Network & $\$ 96,619,124$ \\
\hline The Town & $\$ 92,173,235$ \\
\hline Red & $\$ 90,356,857$ \\
\hline Percy Jackson \& the Olympians: The Lightning Thief & $\$ 88,761,720$ \\
\hline The King's Speech & $\$ 138,797,449$ \\
\hline
\end{tabular}

To exclude the influence of random numbers, we conducted 30 simulations for each movie and calculated the average value of these results, following Kamimura et al (2006). For each movie, the simulation period began four weeks before the movie's release date $(t=-4)$. Table 4 outlines the parameters used in the simulation. $\mathrm{pb}$ is standardised on a scale from one to ten in correspondence to each production budget. Similarly, adv is standardised on a scale from one to ten corresponding to estimated advertising budgets. Because advertising budgets of movies are available only from 2002 to 2004, and the amount of advertising budgets are unlikely to have changed over the past decade, we estimated the advertising budgets of target movies to be within a range of $\$ 30,000,000$ to $\$ 70,000,000$, based on the available data. These data were obtained from 'The Numbers (http://www.the-numbers.com/boxoffice/2010).' pre is rated on a scale from one to ten corresponding to sales figures of previous movies and original novels. These data are available at 'The Numbers (http://www.the-numbers.com/box-office/2010),' and 'The Comics Chronicles (http://www.comichron.com/titlespotlights.html), respectively.

Table 4: Characteristics of the target movies

\begin{tabular}{|l|c|c|c|c|c|}
\hline \multicolumn{1}{|c|}{ Title } & $\boldsymbol{p b}$ & $\boldsymbol{a d} \boldsymbol{v}$ & $\boldsymbol{p r e}$ & Genre & Rating Score \\
\hline Toy Story 3 & 10.0 & 6.2 & 3.8 & Adventure & 8.84 \\
\hline Alice in Wonderland & 10.0 & 5.7 & 5.0 & Adventure & 7.18 \\
\hline Iron Man 2 & 8.5 & 5.9 & 8.8 & Adventure & 7.27 \\
\hline The Twilight Saga: Eclipse & 3.4 & 4.7 & 9.6 & Drama & 6.86 \\
\hline Inception & 8.0 & 5.5 & 0.0 & Sci-Fi & 8.25 \\
\hline $\begin{array}{l}\text { Harry Potter and the } \\
\text { Deathly Hallows: Part I }\end{array}$ & 6.3 & 6.3 & 4.7 & Adventure & 7.92 \\
\hline Shrek Forever After & 8.3 & 5.8 & 3.7 & Adventure & 5.75 \\
\hline The Book of Eli & 4.0 & 4.2 & 0.0 & Action & 6.33 \\
\hline The Social Network & 2.0 & 4.0 & 0.0 & Drama & 8.23 \\
\hline The Town & 1.8 & 3.8 & 0.0 & Drama & 8.54 \\
\hline Red & 3.0 & 3.9 & 0.0 & Action & 7.80 \\
\hline
\end{tabular}

Journal of Technology Management for Growing Economies, Volume 5, Number 1, April 2014 


\begin{tabular}{|l|c|c|c|c|c|}
\hline \multicolumn{1}{|c|}{ Title } & $\boldsymbol{p} \boldsymbol{b}$ & $\boldsymbol{a d} \boldsymbol{v}$ & $\boldsymbol{p r e}$ & Genre & Rating Score \\
\hline $\begin{array}{l}\text { Percy Jackson \& the Olym- } \\
\text { pians: The Lightning Thief }\end{array}$ & 4.8 & 3.5 & 0.0 & Adventure & 7.03 \\
\hline The King's Speech & 0.8 & 4.1 & 0.0 & Drama & 8.25 \\
\hline
\end{tabular}

Figure 2 shows examples of trends in the cumulative adoption rate of actual data and the results of our simulation. We calculated the cumulative adoption rate by dividing the number of cumulative movie viewers at week $t$ by the total number of movie viewers of Toy Story 3 (the movie with the highest boxoffice take among the 13 sample movies).
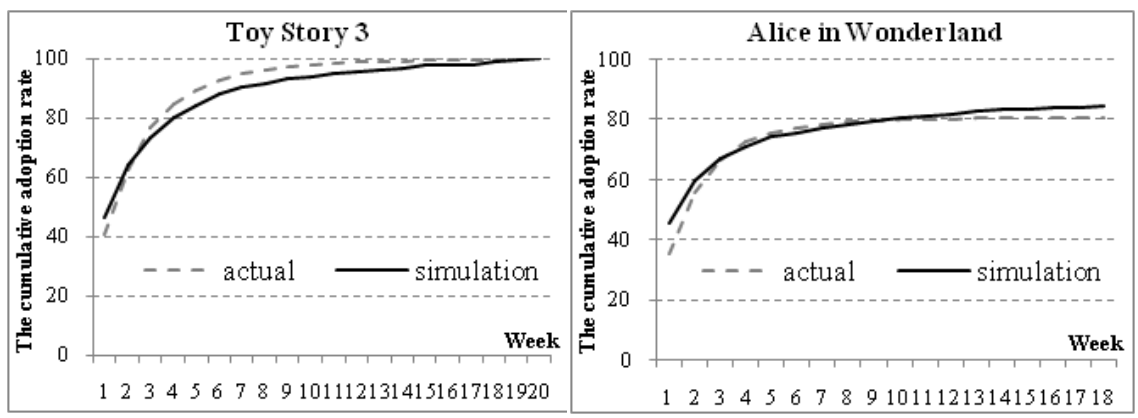

Figure 2: Trends in actual data and results of the simulation (\%).

Table 5 summarises the mean error rate. The error rate at week $t$ is computed by equation (8).

$$
E r_{t}=\frac{\mid S_{t}-A_{t}}{A_{t}}
$$

where $E r_{t}$ is the error rate at week $t, S_{t}$ represents the simulation results at week $t$ and $A_{t}$ is the actual data at week $t$.

Table 5: Mean error rates

\begin{tabular}{|l|c|}
\hline Title & Mean error rate (\%) \\
\hline Toy Story 3 & 3.73 \\
\hline Alice in Wonderland & 3.99 \\
\hline Iron Man 2 & 2.37 \\
\hline The Twilight Saga: Eclipse & 9.51 \\
\hline Inception & 4.01 \\
\hline Harry Potter and the Deathly Hallows: Part I & 3.60 \\
\hline
\end{tabular}


Arai, Y.

Kajiyama, T.

Ouchi, N.

\begin{tabular}{|l|c|}
\hline Title & Mean error rate (\%) \\
\hline Shrek Forever After & 8.56 \\
\hline The Book of Eli & 6.60 \\
\hline The Social Network & 9.43 \\
\hline The Town & 8.67 \\
\hline Red & 7.07 \\
\hline $\begin{array}{l}\text { Percy Jackson \& the Olympians: The Lightning } \\
\text { Thief }\end{array}$ & 6.24 \\
\hline The King's Speech & 11.40 \\
\hline
\end{tabular}

As shown in Table 5, the resulting mean error rates can be considered small. Therefore, these results demonstrate that our proposed model can describe actual consumer behaviour.

\section{Simulations for clarifying the impact of social networks on consumer behaviour}

In this section, we conducted simulations to clarify the impact of social networks on consumer behaviour and the diffusion process of products. In order to consider the characteristics of products, we classified movies into four types by consumers' expectations for a movie and the rating score as shown in Table 6. Consumers' expectations can be represented by.We analysed the impact of the characteristics of movies on the number of movie viewers.

Table 6: Four movie types

\begin{tabular}{|c|c|c|}
\hline Type & Expectations & Rating score \\
\hline 1 & High (9.0) & High (8.5) \\
\hline 2 & Low (3.5) & High (8.5) \\
\hline 3 & High (9.0) & Low (4.5) \\
\hline 4 & Low (3.5) & Low (4.5) \\
\hline
\end{tabular}

In addition, in order to clarify the impact of social networks on the number of movie viewers, we set the following two conditions: (a) social networks' WOM is not considered and (b) social networks' WOM is considered.

Figure 3 illustrates the results of this analysis. The cumulative adoption rate in Figure 3 is calculated by dividing the number of cumulative movie viewers at week $t$ by the total number of movie viewers in the case where social networks' WOM is not considered. 

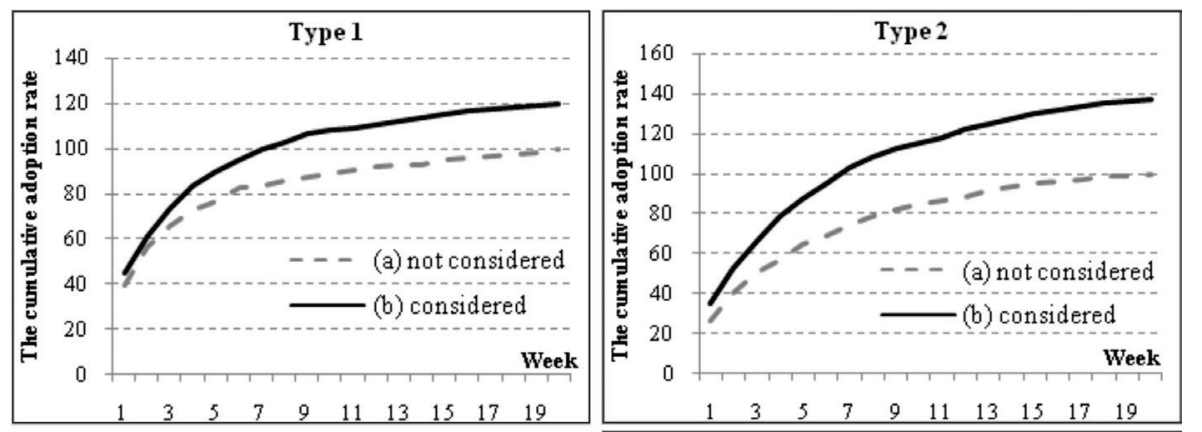

Impact of Social

Networks on

Diffusion
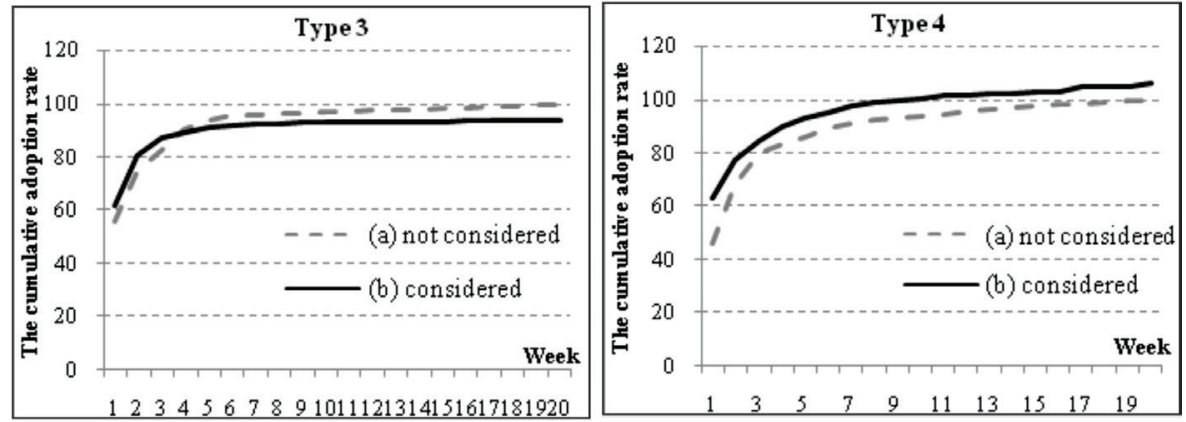

Figure 3: A comparison of simulation results (\%)

Results show that for movies of genre Type 1, Type 2 and Type 4, the number of adopters increases when social networks' WOM is considered. In contrast, for movies of genre Type 3, the number of adopters decreases when social networks' WOM is considered.

For movies of genre Type 1 and Type 2, social networks positively influence the number of adopters because positive WOM spreads more readily through social networks for movies of these genres. However, for movies of Type 3 and Type 4, the number of adopters decrease, as negative WOM spreads more readily through social networks and prevents potential consumers from watching the movies. However, because movies that are classified as Type 4 are low with respect to consumers' expectations and not very well recognised, social networks have a more substantial role in allowing consumers to learn about the movies and subsequently watch them. As a result, for Type 4 movies, the positive effect of social networks exceeds the negating effect of negative WOM, and the total number of adopters increases.

\section{Application to Diffusion Strategies}

To clarify the effective method of weekly advertising budget allocation, we conducted simulations with our proposed model. Specifically, we set four patterns of advertising budget allocation: (i) focusing on the period around 
Arai, Y.

Kajiyama, T.

Ouchi, N.

a release date (standard), (ii) focusing on the period before a release date (before), (iii) focusing on the period after a release date (after) and (iv) same weight during a period (constant). These strategies are outlined in Figure 4.

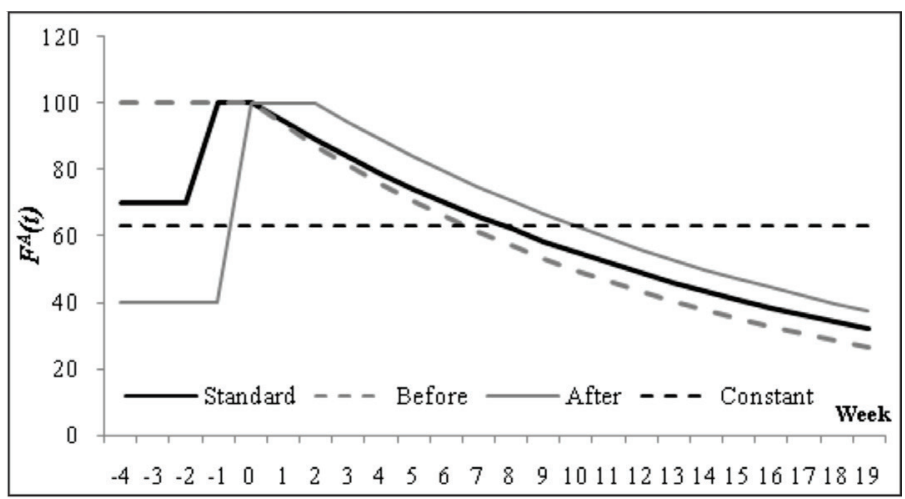

Figure 4: The four patterns of advertising budget allocation (\%)

Figure 5 compares the total number of movie viewers for each condition. In Figure 5, the y-axis is standardised by dividing the total number of movie viewers under each condition by the total number of movie viewers under the condition where movie type is Type 1, allocation pattern is standard and social networks' WOM is not considered.
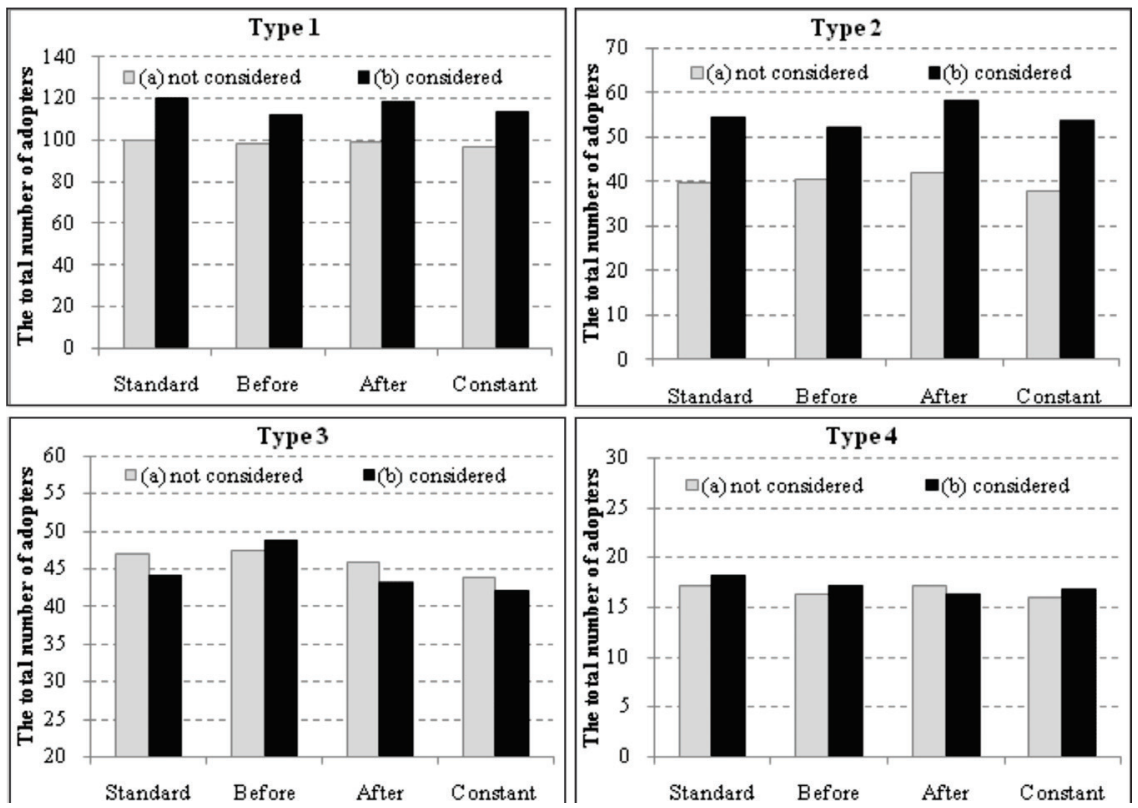

Figure 5: A comparison of the simulation results (\%)

Journal of Technology Management for Growing Economies, Volume 5, Number 1, April 2014 
The results illustrated in Figure 5 provide a wide variety of valuable insights. For example, for Type 2 movies, the effective budget allocation strategy involves using the budget after the movie is released. In contrast, standard allocation strategies are best for movies of Type 1 and Type 4. This result may occur because a positive WOM is stimulated by the effects of postrelease advertising, thereby drawing moviegoers to watch the film. In contrast, for Type 3 movies, allocating the budget prior to the movie's release represents the effective strategy. This result suggests that it is possible to successfully incite a number of individuals to see the movie before negative WOM spreads. In addition, differences in the number of movie viewers across budget allocation patterns become large when social networks' WOM is incorporated into the model.

These results have important implications, particularly for firms' public relations managers. When social networks are not developed, changes in weekly advertising budget allocation do not significantly affect the number of individuals that adopt products. However, when consumers receive information through social networking services, different budget allocation strategies can significantly impact the adoption rate. Therefore, it is of great importance to select the effective method of weekly advertising budget allocation when social networks are pervasive. In addition, this study suggests that the appropriate manner of this allocation depends on consumers' pre-release expectations regarding a movie. Therefore, sharing information between the creative department and the public relations department is more critical when determining how to allocate an advertising budget. These findings may apply to other contexts that are strongly influenced by the effects of advertising and WOM.

\section{CONCLUSION}

In this study, we constructed a model of consumer behaviour that accounts for social networks. The results of our simulations that utilise this model demonstrate the impact of social networks on consumer behaviour and product diffusion. Further, we applied our model to the diffusion strategies to determine effective weekly strategies concerning advertising budget allocation. As a result of these steps, we demonstrated that social networks tend to positively affect product diffusion, except for products for which consumers had high expectations but evaluated poorly. In addition, we identified effective weekly advertising budget allocation strategies corresponding to the characteristics of movies, and showed that the different allocation patterns of the weekly advertising budget have a greater impact on the number of adopters as social networks grow.
Impact of Social

Networks on Diffusion 
Arai, Y.

Kajiyama, T.

Ouchi, N.
This study provides new insights on two fronts. First, it clarifies the impact of social networks on consumer behaviour and the diffusion process of products quantitatively, which had remained unclear in the past. Second, this study provides suggestions for effective diffusion strategies that account for the impact of social networks. As a result of these theoretical and practical contributions, this study is useful for firms to effectively diffuse their products, even with limited budgets. The results of this study are particularly useful for firms in emerging economies whose budgets are relatively small relative to large firms in developed economies.

Future researchers in this domain should seek to apply our model to other product markets. In addition, future research should evaluate multinational strategies with a consideration of social networks.

\section{END NOTES}

See appendix for the relationship among the equations in our model.

\section{REFERENCES}

Barabasi, A. L. and Albert, R. (1999) 'Emergence of Scaling in Random Networks', Science, 286, pp. 509-512. http://dx.doi.org/10.1126/science.286.5439.509.

Bass, F. M. (1969) 'A New Product Growth Model for Consumer Durables', Management Science, 15:1, pp. 215-227. http://dx.doi.org/10.1287/mnsc.15.5.215.

Duan, W., Gu, B. and Whinston, A. B. (2008) 'The Dynamics of Online Word-of-Mouth and Product Sales -An Empirical Investigation of the Movie Industry', Journal of Retailing, 84:2, pp. 233-242. http://dx.doi.org/10.1016/j.jretai.2008.04.005.

Kamimura, R., Masuda, H. and Arai, T. (2006) 'An Agent-Based Model of Consumer Behaviour: Application to the Movie Market', Journal of Japan Industrial Management Association, 57:5, pp. 450-469 (in Japanese).

Libai, B., Muller, E. and Peres, R. (2009) 'The Diffusion of Services', Journal of Marketing Research, 46,:2, pp. 163-175. http://dx.doi.org/10.1509/jmkr.46.2.163.

Mahajan, V., Muller, E. and Bass, F. M. (1990) 'New Product Diffusion Models in Marketing: A Review and Direction for Research', Journal of Marketing, 54:1, pp. 1-26.

Mansfield, E. (1961) 'Technical Change and the Rate of Imitation', Econometrica, 29:4, pp. 741-766.

Meyer, P.S. (1994) 'Bi-Logistic Growth', Technological Forecasting and Social Change, 47:1, pp. 89-102.

Mittal, V., Kumar, P. and Tsiros, M. (1999) 'Attribute-Level Performance Satisfactions, and Behavioural Intentions over Time: A Consumptions-System Approach', Journal of Marketing, 63;2, pp. 88-101. http://dx.doi.org/10.2307/1251947.

Miyata, K. and Ikeda, K. (2008), 'The Internet Changes Consumer Behaviour (NETTO GA KAERU SHOUHISYA KODO)', Tokyo, NTT Publishing Co., Ltd. (in Japanese).

Plouffe, C. R., Vandebosch, M. and Hulland, J. (2001) 'Intermediating Technologies and MultiGroup Adoption: A Comparison of Consumers and Merchant Adoption Intentions toward a New Electric Payment System', Journal of Product Innovation Management, 18:2, pp. 65-81. http://dx.doi.org/10.1111/1540-5885.1820065.

Rogers, E. M. (1962), 'Diffusion of Innovations', New York, The Free Press.

Journal of Technology Management for Growing Economies, Volume 5, Number 1, April 2014 
The Comics Chronicles (2011) 'Title Spotlights', (online) (cited 1 July 2011). Available from <URL: http://www.comichron.com/titlespotlights.html>.

The Numbers (2011) 'Theatrical Box Office Chart Calendar for 2010', (online) (cited 1 July 2011). Available from <URL: http://www.the-numbers.com/box-office/2010>.

Impact of Social

Networks on

Diffusion

Tilman, A. S., Gunter, L. and Jurgen, R. (2007) 'Agent-Based Simulation of Consumer Behaviour in Grocery Shopping on a Regional Level', Journal of Business Research, 60:8, pp. 894-903. http://dx.doi.org/10.1016/j.jbusres.2007.02.005.

Tsui, H. C. (2012) 'Advertising, Quality, Willingness-to-Pay: Experimental Examination of Signaling Theory', Journal of Economic Psychology, 33:6, pp. 1193-1203. http://dx.doi. org/10.1016/j.jbusres.2007.02.005.

Yudai Arai, Graduate School of Science and Engineering, Aoyama Gakuin University, Japan. Email: c5612119@aoyama.jp.

Tomoko Kajiyama, Department of Industrial and Systems Engineering, Collage of Science and Engineering, Aoyama Gakuin University, Japan.

Email: tomo@ise.aoyama.ac.jp.

Noritomo Ouchi, Department of Industrial and Systems Engineering, Collage of Science and Engineering, Aoyama Gakuin University, Japan.

Email: ouchi@ise.aoyama.ac.jp. 
Arai, Y.

Kajiyama, T.

Ouchi, N.

\section{APPENDIX}

Relationships among equations in our model

\section{0}

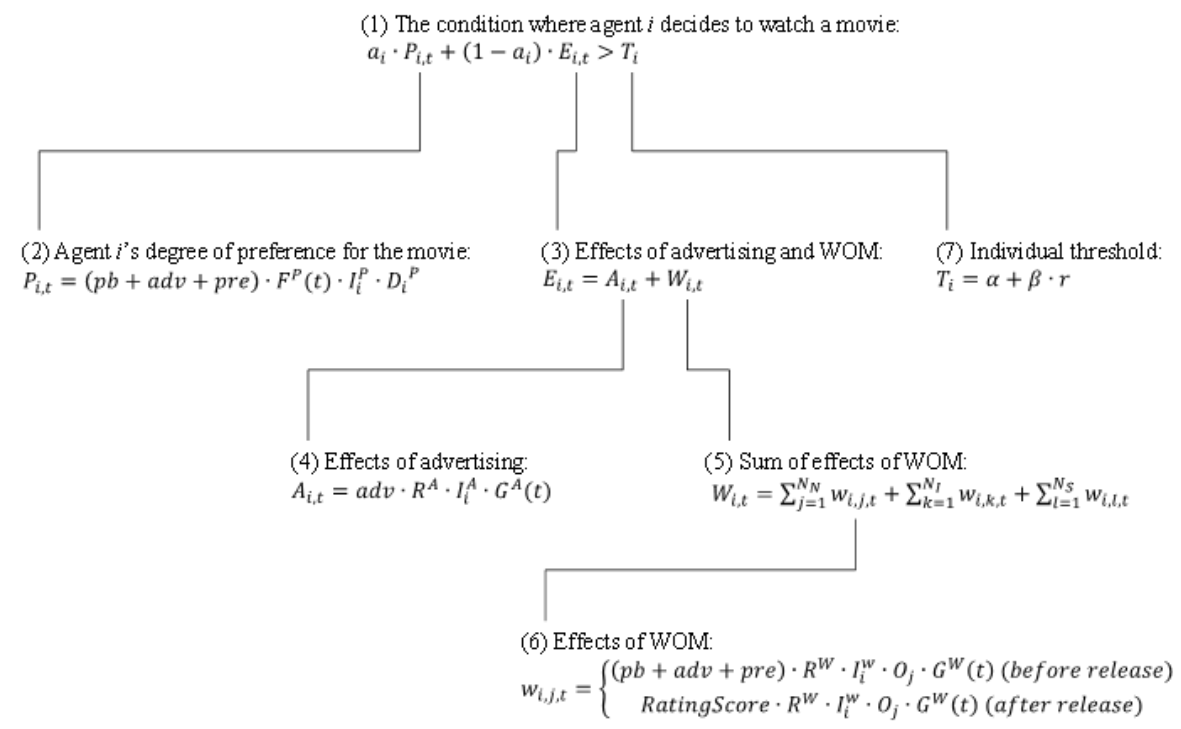

Journal of Technology Management for Growing Economies, Volume 5, Number 1, April 2014 